\title{
En torno al pensamiento de Binford
}

\author{
Mario Orellana $R$.
}

Aprovechando la publicación, en 1994, de la tercera edición del libro de L.R. Binford, "En busca del pasado", hecha por la Ed. Crítica, Barcelona, intentamos dar a conocer el pensamiento del autor, en cuanto se refleja en el libro citado; pero, también, exponer nuestras reflexiones críticas sobre sus ideas, y, obviamente la de otros autores, tales como I. Hodder.

Según Colin Renfrew, que escribe el prólogo, Binford es "el pensador más prominente de nuestra época en el campo de la arqueología". Aunque parezca exagerado este juicio, sin duda que el arqueólogo norteamericano ha influido fuertemente en muchos arqueólogos del nuevo mundo, que hicieron suya las orientaciones metodológicas y teóricas de la arqueología procesual o "nueva arqueología". Como es bien conocido Binford fue uno de los líderes de este nueva corriente de pensamiento arqueológico, que se inició a comienzos de la década de 1960.

En el Prefacio (págs. 16-21) el autor confiesa que su obra "no presenta los resultados de una investigación y pensamiento completos sino que se trata, más bien, de una especie de ensayo sobre los avances conseguidos en diversos temas" incluyendo también sus opiniones sobre el trabajo de otros investigadores.

Binford recuerda que hace algunos años perfiló un programa de investigación de largo alcance proponiendo que los estudios sobre los restos de fauna, sobre el uso organizado del espacio y sobre los sistemas ecológicos fuesen considerados los más provechosos para el desarrollo de una teoría explicativa en arqueología. Esto ocurría en 1977. En el libro que comentamos centró la discusión en el análisis espacial "en términos de nuestro conocimiento sobre la variabilidad existente tanto en cada uno de los yacimientos como al comparar los yacimientos entre sî".

Binford, en general, insiste en el valor de la investigación etnológica para un mejor conocimiento del pasado cultural que se estudia. Según él, las 
actuales poblaciones nómadas "marcan" su medio con restos arqueológicos y asegura que "un mismo pueblo produce muchos tipos diferentes de restos arqueológicos". Esta última hipótesis la utiliza para discutir con F. Bordes sobre el significado de los diferentes musterienses conocidos en Francia, en el Paleolítico Medio (Segunda Parte, págs. 87-116).

Lo que interesa a Binford y a los arqueólogos, en general, es mejorar los métodos de inferencia. No es suficiente, sin embargo, pensar que "el desarrollo de los métodos depende en principio de otras ciencias". Frecuentemente se encuentran los arqueólogos "con que las inferencias obtenidas de este modo no son quizás ni útiles ni adecuadas para la solución de nuestros problemas arqueológicos". Sólo los arqueólogos serán capaces de realizar las investigaciones pertinentes para lograr los objetivos arqueológicos, al margen de las ayudas que puedan proporcionarles otras disciplinas. Es decir, los arqueólogos están obligados a "desarrollar una ciencia de la arqueología".

Según Binford "las técnicas empleadas por los filósofos sociales representan el extremo opuesto". Se refiere concretamente a los marxistas, estructuralistas, materialistas, idealistas, etc. Estos "creen que sus posturas favorecen la comprensión e inteligibilidad del mundo". Usando "argumentos acomodaticios "post hoc"' utilizan el registro arqueológico para verificar sus teorías.

El libro de Binford trata de cómo se da sentido a la experiencia arqueológica y de la forma en que se están usando tales experiencias, una vez convertidas en testimonios significativos del pasado; todo lo anterior para explorar dicho pasado y valorar las ideas acerca de él.

En "descifrando el registro arqueológico" (págs. 23-24) el arqueólogo norteamericano señala que "los arqueólogos son algo más que simples descubridores". El registro arqueológico está enterrado, y puede ser descubierto de muchas maneras; al serlo está con nosotros, en el presente. Entonces, "las observaciones que hacemos sobre él están aquí, ahora, son nuestras contemporáneas. No son observaciones directas que sobreviven del pasado".

Contestándole a otros arqueólogos que lo han criticado (post-procesualistas) escribe "el registro arqueológico no se compone de símbolos, palabras o conceptos, sino de restos materiales y distribuciones de materia" y agrega que el único modo de poder entender su sentido es averiguando cómo llegaron a existir esos materiales, cómo se han modificado y cómo adquirieron las características que los arqueólogos estudian ahora, en el presente. Los vestigios materiales son las consecuencias de las actividades humanas del pasado. "El desafío que la arqueología plantea consiste en la transcripción, de manera literal, de la información estática contenida en los restos materiales observables para reconstruir la dinámica de la vida en el pasado y estudiar las condiciones que han hecho posible que estos materiales hayan sobrevivido y llegado hasta nosotros".

Sin embargo, parece prudente recordar que los restos arqueológicos no sólo son "materiales", sino que son instrumentos, artefactos de todo tipo, 
pequeños o monumentales, que fueron construidos para diversos fines, y que por lo tanto tenían sentido; fueron hechos por hombres con ideas, creencias, problemas y soluciones, preguntas y respuestas. Son por lo tanto materiales e ideacionales, son también conceptos y símbolos.

Además, como lo ha escrito Hodder en el libro "Interpretación en Arqueología", la "cultura material" no es sólo el reflejo simple y directo del comportamiento humano. No basta tener instrumentos independientes para leer los datos arqueológicos; es necesario considerar los principios de estructuración históricamente contextuales.

Los arqueológos sabemos que los procesos culturales que forman el registro arqueológico son muy complejos porque no son independientes de nuestra interpretación de la cultura y de la sociedad del presente, en donde vivimos.

Pero, volviendo al pensamiento de Binford ¿cómo aspira a obtener conocimiento y lograr construir "la dinámica" cultural del pasado? No le bastan los métodos históricos, ni los provenientes de las ciencias sociales. Incluso los que pertenecen a las ciencias naturales, que recomienda usar, no resuelven completamente sus preguntas. Entonces, para buscar una solución metodológica, para encontrar instrumentos teóricos que le permitan encontrar el sentido a los elementos del pasado, recomienda estudiar a las poblaciones presentes, conocer sus yacimientos, sus desplazamientos, como distribuyen sus instrumentos (capítulos 5 y 6); junto a la etnoarqueología, recomienda también hacer arqueología experimental y no dejar de estudiar todos los documentos históri$\cos$, incluyendo las fotografías. En resumen, de acuerdo a Binford, tendrían los arqueólogos tres importantes campos de investigación: el estudio de los pueblos contemporáneos, especialmente los grupos de economías y tecnologías preindustrial; la creación de situaciones experimentales que nos permitieran controlar las causas y estudiar los efectos y el uso de la variada documentación histórica.

¿Pero qué quiere conocer del pasado el arqueólogo? Esta vez Binford selecciona tres grandes conjuntos de problemas: en primer lugar. saber acerca de los rasgos fundamentales de la conducta de nuestros antepasados más antiguos; conocer acerca del comportamiento típicamente humano y cuándo comenzó. ¿Era un cazador o sólo un carroñero? ¿Las características humanas (que nos distinguen de otros animales) se iniciaron al mismo tiempo o bien eran emergentes, es decir surgieron en contextos diferentes? (capítulos 2-3-4). Un segundo conjunto de problemas se refieren al origen de la agricultura y a las condiciones que llevaron al hombre a adoptar unas formas de vida sedentarias. En el capítulo 8 analiza este conjunto de problemas. Por último, un tercer grupo de problemas se refiere a los orígenes de la civilización, a la complejidad de la vida urbana, tanto política como social (capítulo 9).

En resumen la Arqueología inicia sus investigaciones preguntándose por las características y el sentido del pasado humano más remoto y prosigue "a 
lo largo de toda la evolución hasta la complejidad del mundo moderno". Los arqueólogos inician sus estudios científicos con los objetos materiales "y es natural que adopten punto de vista materialistas; a menudo, avanzan argumentos de naturaleza pragmática en contextos donde son mucho más corrientes los argumentos de tipo psicológico".

Tenemos así un bosquejo, de acuerdo a lo que ha escrito Binford, de su perfil ideológico: es evolucionista, es materialista (no marxista), es pragmático conductista y ecologista y le atraen las metodologías de las ciencias naturales, aunque no desdeña las metodologías sociales y concretamente las antropológicas; a su vez intenta pensar la arqueología buscando dar sentido a los restos arqueológicos, insistiendo en las investigaciones que superen los trabajos particularistas y provincianos; la investigación arqueológica es cada vez más internacional y comprende cada vez más amplios períodos de tiempo y extensas áreas geográfica.

Uno de los aportes más interesantes en la línea de la epistemología arqueológica es el intento de Binford de superar respuestas generales o globales, y abocarse a encontrar explicaciones o teorías de rango o alcance medio.

Ocurre que los arqueólogos siempre han hecho inferencias para conocer el pasado sin tomar en consideración la calidad de los métodos empleados. Siguiendo a W. Taylor considera que los arqueólogos pueden hacer generalizaciones yendo más allá de sus datos empíricos. Binford tratará de crear métodos para llevar a cabo inferencias exactas e intentará evaluarlas y verificarlas. En los capítulos 2 y 3 (págs. 39-82), revisará algunas inferencias hechas por otros prehistoriadores y presentará las suyas, todas relacionadas con la pregunta ¿era el hombre más antiguo un cazador?

Se trata entonces de hacer inferencias que puedan ser puestas a prueba haciendo uso de una combinación de métodos científicos, en donde se encuentran los estudios etnoarqueológicos, zooarqueológicos, geológicos, medio ambientales y obviamente arqueológico (excavaciones - análisis líticos contextos culturales). Todas estas informaciones ¿ayudan al arqueólogo a conocer el comportamiento humano de hace 2 millones de años?

La metodología de Binford intenta en primer lugar conocer cómo se formó un depósito, el contexto arqueológico y paleontológico; lo hace preguntando qué elementos son conocidos y cuáles no; así este elemento desconocido podrá relacionarse con la actividad humana. En el caso de los estudios de Leakey en Olduvai, usando una variedad de métodos, explicó muchos contextos paleontológicos por la acción de los carroñeros; pero también constató que en algunos yacimientos del paleolítico inferior había una cantidad de materiales óseos que no podían explicarse por lo que se sabe acerca de los carnívoros africanos. Había una cantidad importante de huesos largos de las patas, que conservan el tuétano y conjuntos de piedras usados como percutores, mazas, choppers. En estos niveles inferiores, los más antiguos, las lascas eran raras y 
los raspadores no existían. En estos depósitos situados en antiguas playas lagunares la ausencia de instrumentos pequeños (lascas) muestra que no se cortaba carne, ni meno se cazaba; solamente se quebraban huesos y se rescataba la médula de éstos.

Posteriormente hacia los 600.000 años aparecen instrumentos cortantes y huesos de animales; aquí se puede inferir que la caza comenzaba a ser un medio de alimentación importante.

Como, según Binford, existe una estandarización en los datos; y hay un esquema repetido de frecuencia de huesos residuales en los niveles inferiores de los depósitos de Olduvai (período geológico pliopleistoceno) se puede inferir que los primeros grupos humanos, incluso por cientos de miles de años, no fueron cazadores sino que marginales carroñeros. Estamos entonces ante una nueva explicación, que se piensa que puede resistir la contrastación empírica. Los homínidos — de acuerdo a la interpretación dinámica de la formación de los depósitos - no transportaban su comida a las áreas de dormitorio, ni parecen tener pequeños grupos familiares. Sin embargo hay datos contradictorios con los resultados de las excavaciones en África Oriental y en África del Sur. Según Binford los prehistoriadores de África Oriental (Leakey-Isaac), han utilizado "una serie de convenciones y argumentos post hoc".

Binford pone a prueba las interpretaciones de $\mathrm{G}$. Isaac estudiando las charcas en la actualidad; en ellas se encuentran abudantes restos de fauna, animales muertos, huesos mordisqueados por las hienas, leones, y picoteados por buitres y otros animales. El estudio arqueológico de una charca antigua muestra a su vez restos de huesos y pocas evidencias de instrumentos; estas concentraciones mayores o menores se producen por diferentes causas, que a su vez explican la situación actual del antiguo yacimiento, no siendo acertado asegurar contemporaneidad de las asociaciones aparentes de huesos y artefactos.

Sin embargo nos ha llamado la atención que Binford no maneje - por lo menos en los capítulos de este libro- los datos antropológicos físicos, que nos informan que en algunos casos estamos ante la presencia de homínidos prehombres y en otros del Homo Erectus, con antigüedad probable de 1 millón de años. Nuestra interpretación hipotética es que la evidencia de los yacimientos asociados con Homo Erectus permite sostener que estamos ante cazadores y no solamente ante carroñeros; cazadores que sí tienen su hábitat más complejo y por lo tanto diversificado.

Pasando al Pleistoceno Medio, Binford sostiene que muchos yacimientos del período Achelense (Paleolítico Inferior) proporcionan grandes cantidades de instrumentos líticos, que en muchos casos estaban modificados por el uso. Además sostiene que el uso de cuevas y abrigos rocosos son raros; y que los yacimientos están directamente asociados con fuentes de agua.

Sigue sosteniendo para este período su opinión que los lugares cercanos a las fuentes de agua eran lugares elegidos por estos Hombres Achelenses para 
carroñar; no siendo, entonces, lugares de ocupación, es decir, áreas domésticas en donde se compartían los productos de sus actividades de caza. Esto último sólo habría ocurrido con el Achelense Superior y en el Paleolítico Medio de África o Musteriense Europeo.

Binford insiste que una investigación que busca explicaciones contrastables no puede apoyarse sólo en el aumento de testimonios del registro arqueológico. Necesitamos métodos de inferencia sólidos; no es suficiente, entonces, reconocer que las cosas pueden haber ocurrido de una manera y proponer juicios sobre lo que parece más aceptable.

El esfuerzo de Binford por poner a pruebas explicaciones arqueológicas referidas a los primeros grupos de seres humanos, se apoya en construir métodos independientes de las opiniones y visiones que se tienen del pasado más antiguo del Hombre. Nos parece, a igual que otros críticos, que estos métodos o instrumentos de medición no pueden independizarse del marco teórico que tiene el arqueólogo, que a su vez se sitúa dentro de un contexto cultural e histórico particular.

De todos modos, las explicaciones que ofrece Binford pueden satisfacer o no a los especialistas del Paleolítico Inferior; pero lo que no se puede discutir es que están bien organizadas y apoyadas en un conjunto de datos y de métodos rigurosos. Pero curiosamente se trata de explicaciones de carácter general; lo que nos está diciendo el arqueólogo norteamericano es que los Homínidos del PlioPleistoceno (Australopitecos-Homo Habilis) vivían de la práctica carroñera y no eran cazadores; estamos, entonces, ante una nueva interpretación que reemplaza a otra, pero que tienen de común su intención de responder en forma global lo que ocurría hace tres o dos millones de años atrás.

En la segunda parte de su libro (capítulos 4, 5, 6 y 7) Binford se pregunta ¿qué significa? el conjunto de observaciones detalladas que se explican por los modelos construidos; éstos se han logrado luego de intensas investigaciones sobre el registro arqueológico. Dicho de otra manera, intenta saber "¿qué sucesos del pasado están reflejados en los modelos establecidos por los arqueólogos?".

En el capítulo titulado "el desafío del musteriense" (págs. 87-102) recuerda que desde los inicios de la Arqueología dos problemas son fundamentales: ¿cómo se puede describir, en términos formales, la variabilidad de las cosas que perduran del pasado? y ¿cómo se distribuye cronológica y geográficamente la variabilidad observada? Así, para responder a estas preguntas pasa revista a diversas respuestas teóricas, modelos evolutivos, progresistas, modelo "philaparalelos" (tradiciones culturales paralelas); modelo de cultura de Gordon Childe, modelo étnico (relación cultura-pueblo), etc.

Binford escribe que las innovaciones de $\mathrm{F}$. Bordes que se refieren a un sistema de clasificación de artefactos líticos y a técnicas de descripción cuantitativa de los conjuntos líticos, se inscribieron en una visión antigua del pasado, de tipo biológico u orgánico. Este "antiguo modelo" entraba en 
oposición con el modelo etnográfico-etnológico norteamericano (distribución espacial de artefactos de etnias actuales). Según el modelo de Bordes, para el estudio del período Musteriense, habían culturas persistentes e industrias alternantes; Binford no está de acuerdo con estas conclusiones y pretende refutarlas y para esto, parte de un concepto de cultura diferente (análisis etnográfico de los indios americanos).

¿Qué significado debía darse a la variabilidad estudiada en las industrias del Musteriense europeo? La hipótesis de Binford afirmaba que diferentes tipos de actividad debían haberse combinado de formas distintas para producir asociaciones de artefactos y de restos faunísticos, y por tanto que deberían encontrarse cierto tipo de correlación entre algunas actividades y determinados subproductos de los restos de consumo de alimentos (huesos de animales); igualmente debería existir algún tipo de relación entre los diversos artefactos relacionados con la obtención, elaboración y consumo de animales.

Luego de investigar los yacimientos y las asociaciones musterienses de Francia, con el apoyo de Bordes, ninguna de las correlaciones que hizo le proporcionó suficiente información como para indicarle la razón de ellas; las correlaciones estaban allí en el registro arqueológico, como modelos comnplejos de asociación estática, pero no tenía cómo explicarlas.

¿Cómo encontrar la relación entre causas dinámicas (del pasado) y consecuencias, ahora, estáticas? ¿Cómo conocer el comportamiento dinámico del pasado humano? Buscó, entonces, estudiar entre los pueblos esquimales cazadores actuales, sus sistemas de vida, de caza, sus desplazamientos cíclicos, sus usos de espacios, su distribución de artefactos, etc. Así si tenía éxito podría hacer inferencias correctas de los datos arqueológicos musterienses. La pregunta era si podría aplicar sus estudios de los esquimales nunamiut, cazadores de renos, a otros pueblos cazadores de renos, que habían vivido hace por lo menos 50.000 años atrás. Si tenía éxito Binford podría desarrollar un cuerpo de inferencias aplicables a la arqueología. Estos estudios etnográficos y etnoarqueológicos los relata en los capítulos 6 y 7; también en el capítulo 7 expone sus experiencias en Australia con grupos aborígenes, que en la década del ' 70 fabricaban artefactos líticos.

Todo este proyecto de investigaciones (estudio metodológico de los conjuntos de huesos; organización espacial de los restos de actividades y estructura de los yacimientos; estudios comparativos globales de cazadores y recolectores) lleva a Binford a considerar que se apartó de algunas ideas imperantes de la Nueva Arqueología de las décadas del '60 y '70. Incluso reflexiona sobre el mal uso que se hizo de la deducción y del concepto de Arqueología Social; en pocas palabras escribe que el camino que ha seguido su investigación durante las dos últimas décadas ha sido a menudo divergente del recorrido por la Nueva Arqueología.

Binford estudia los pueblos cazadores actuales para conocer su "dinámica" social y cultural, y así, en cuanto arqueólogo, hacer uso de las conclusiones 
etnoarqueológicas para intentar construir modelos de inferencias referidos al pasado. Entre sus conclusiones están: a) no es correcto a la luz de los datos etnográficos (nunamiut), suponer que un grupo de gentes generan yacimientos internamente homogéneos; b) no se ve refrendada por la observación actual que la mayor proximidad de yacimientos entre sí corresponde a una mayor similitud; c) se puede suponer que cuanto más intensa es la utilización de un lugar más variado serán los distintos tipos de asentamientos y yacimientos en dicho lugar; d) cada yacimiento es el reflejo de la secuencia única de usos que motivaron en el pasado su emplazamiento en dicho lugar.

Estas conclusiones pueden servir para abordar el tema musteriense, pero como dice Binford "no nos confundamos, estas experiencias etnoarqueológicas no proporcionan soluciones directas al problema musteriense. La conclusión que podamos sacar de mi trabajo entre los nunamiut no significa que mis argumentos funcionales acerca de la variabilidad del Musteriense fuesen correctas, sino más bien que los métodos arqueológicos por inferencia son en general inadecuados". Incluso en la nota 18 del capítulo 6 (pág. 255) Binford recuerda que los esquimales nunamiut no usan artefactos líticos y agrega "una vez más debo puntualizar que no considero que los nunamiut proporcionen una analogía con los grupos paleolíticos".

Hay por lo tanto, que seguir buscando nuevas metodologías. Para esto Binford, en el capítulo 7 estudia la "estructura del yacimiento", es decir qué hace la gente en su espacio de vida. Una de las conclusiones parciales del estudio etnográfico de Binford es que algunos cazadores recolectores modernos se desplazan por un cierto número de lugares llevando a cabo en cada uno de ellos diferentes tipos de actividades. Así los distintos modelos de variabilidad en los conjuntos líticos podían relacionarse con tipos de yacimientos funcionalmente diferentes. Sin embargo, el mismo arqueólogo nos dice que parece "que también existe una serie de rasgos que subyacen permanentemente y que son característicos de la organización especial interna de lá vida de un yacimiento".

Entonces Binford se esfuerza por reconocer los factores que condicionan la organización espacial de las actividades llevadas a cabo en los yacimientos, al margen de su función. Está convencido de que "los rasgos definitorios del carácter de las actividades, la organización del trabajo empleado en su ejecución y el uso previsto de un lugar, en relación al sistema global de subsistencia del asentamiento, están codificadas en la organización de la estructura del yacimiento". Esta conclusión proviene de sus observaciones de los yacimientos esquimales, nunamiut. Define tres conceptos (equipo de herramientas; actividad y áreas de actividades) para conocer mejor la organización ocupacional de un yacimiento, pero con mucha honradez concluye "de que no existe necesariamente una correspondencia exacta entre un lugar y un equipo de herramientas, o incluso entre un espacio y una simple actividad". A pesar de lo anterior sigue creyendo que hay modelos, que hay una estructura situacional 
de los artefactos; y su pregunta es: ¿cómo dar el sentido exacto a los modelos que observamos?

Obviamente que sus respuestas se apoyan en las observaciones que ha realizado sobre los pueblos actuales (esquimales, bosquímanos, australianos, navajos).

Cuando analiza el trabajo de un individuo alrededor de un hogar (del fuego) señala que hay un modelo que parece ser universal; así un joven bosquimano (fig. 82, pág. 159) no se sienta frente al fuego sino a un lado, su cuerpo, así forma un ángulo recto respecto al hogar. Pero cuando da otros ejemplos (figuras 83 y 84 ) ocurre que las fotos muestran a los individuos australiano y navajo frente al fuego y no de lado. Lo único que es igual es que se sitúan a cierta distancia del fuego (entre 50 y $100 \mathrm{~cm}$ ). Entonces no entendemos su afirmación que el modelo ha sido identificado muchas veces. Lo que sí aparece como repetitivo es cuando describe a un grupo de personas sentadas alrededor del hogar, en posición circular.

Sin embargo nos parece más interesante la observación que hace - y que señala que es repetitiva- de un fabricante de artefactos que deja caer las lascas entre sus piernas y formando una especie de arco cuyo tamaño y forma varía, según sea la longitud del brazo del individuo.

Estudiando cómo trabajan los esquimales alrededor del fuego identifica "un modelo ideal" (fig. 89, pág. 163); en donde hay dos zonas de distribución de restos: una llamada "drop" y otra "toss"; las pequeñas astillas caen entre las piernas de los cazadores, los fragmentos más grandes son arrojados hacia atrás de los individuos. Obviamente que si los individuos hacen tareas diferentes en torno al hogar, la distribución de los artefactos (líticos-huesos, etc.) se hace más compleja.

Igualmente Binford hace observaciones interesantes cuando diferencia los hogares, y las actividades que se producen cerca de ellos, en el interior o en el exterior de una habitación: los hogares que están dentro de una "casa" están rodeados de piedras con el fin de impedir que las cenizas se dispersen; en cambio en el exterior los hogares no están rodeados de piedras y las cenizas se esparcen.

A partir del conocimiento etnoarqueológico que tiene, interpreta el comportamiento de los yacimientos paleolíticos franceses (Pincevent, de 15.000 años), rechazando la interpretación de Leroi-Gourhan, que cree encontrar evidencias de una tienda de cazadores con tres hogares.

Binford también encuentra otros modelos referidos a las áreas dormitorios, que derivan del registro etnográfico, y que interesa aplicar a los yacimientos arqueológicos. En este último caso analiza el Abri Pataud perteneciente al Paleolítico Superior de Francia, excavado por H.I. Movius.

En estos modelos se evidencia la influencia de los factores relacionados con el tamaño y mecanismos básicos del cuerpo humano, y si se trata de individuos solos o de parejas o más personas. En el primer caso descubre el 
estudioso un modelo de lecho y hogar alternado; por el contrario, cuando se trata de parejas los hogares no se sitúan entre lechos dobles; cuando el grupo es mixto, los hogares se hallan emplazados entre lechos individuales como dobles. Esta alternación dice Binford "se repite por todo el mundo" y tanto en el presente como en el pasado.

En estas áreas dormitorio, que son muy personales, también se come, sobre todo en la mañana, formándose, así con el tiempo, pequeños basureros. Así tenemos basureros productos de comidas colectivas (en la noche) y los basureros cerca del lecho, pero en ciertos casos el basurero se forma a la salida de la cabaña (bosquimanos).

Luego de examinar algunos modelos espaciales generales que implican actividades particulares (disposiciones de trabajos sentados, áreas dormitorios, lugares amplios para trabajos de pie, etc.) propone analizar los yacimientos arqueológicos "considerándolos como un todo" e investigar "cómo los modelos identificados previamente encajan y conforman un yacimiento completo". Piensa que los modelos espaciales se entremezclan dentro de la estructura de un yacimiento con entidad propia. Volvamos a insistir que estos modelos han sido construidos a partir de los estudios etnográfico-etnológicos (con la perspectiva del arqueólogo), es decir las viviendas y su "estructura situacional" corresponde a ejemplos de campamentos de esquimales (residencia-campamento de caza) de australianos Ngataljara y bosquimanos Kung San (págs. 183-201; en especial véase figura 115).

Pero a pesar del esfuerzo de uniformar campamentos a partir del cuerpo humano y de sus propiedades "que son las mismas para todos los humanos". Binford reconoce que existen diferencias "que pueden ser altamente interesantes". Entonces ¿por qué generalizar y uniformar? Si existen diferencias importantes en los actuales pueblos cazadores ¿cuánto más no habrá entre éstos y los prehistóricos pueblos cazadores, distanciada por decenas de miles de años?

Luego de exponer en forma detallada la "casa Palangana", una vivienda de invierno de los esquimales (figuras 117 a 122) intenta "una teoría acerca de la estructura situacional" (págs. 201-203).

La conclusión principal es que "los distintos conjuntos arqueológicos son expresión de diferencias funcionales, dentro de sistemas únicos y no, necesariamente, diferencias entre sistemas".

El agrupar las cosas que son similares no garantiza que veremos un sistema cultural en términos reales; lo que hay que hacer es todo lo contrario; debemos juntar todos los aspectos arqueológicos diferentes de un mismo sistema.

Satisface, sin embargo, la prudencia de Binford cuando escribe "de todos modos no está de más recordar que queda mucho camino por recorrer antes de que podamos olvidarnos de los artefactos y empezar a reconstruir los contextos dinámicos en los que tales distribuciones tomaron forma". 
En la tercera parte de su libro se pregunta ¿por qué ocurrió?, en relación a dos problemas que siempre han convocado a los arqueólogos: los orígenes de la agricultura y la formación de sociedades complejas (orígenes de la civilización).

Pero antes de tratar estos dos temas (caps. 8 y 9; págs. 210-248) intenta separar bien lo que es una teoría general (que él dice que no usa) de la teoría de alcance medio. "La teoría general implica la existencia de argumentos destinados a explicar por qué razones el pasado era como parece haber sido. La mayoría de las proposiciones teóricas, generadas del estudio de sociedades contemporáneas, implican especulaciones sobre las secuencias de acontecimientos que pueden haber caracterizado la transformación de un modelo de sistema en otro, y no dejan de ser extrapolaciones de un estudio del sistema a otro, con argumentos explicativos de cómo tuvo lugar la transformación" (pág. 208). Es interesante que Binford critique los modelos de Wittfogel y de Sahlins porque, en el fondo estas teorías generales "son una consecuencia inevitable de contar sólo con experiencias etnográficas en el momento de establecer las bases de las especulaciones referentes a los procesos evolutivos". Lo que han hecho muchos arqueólogos ha sido acomodar las observaciones del registro arqueológico a los argumentos teóricos generales, generados por historiadores y etnógrafos. Según Binford estamos ante una argumentación de tipo tautológico.

Apoyándonos en el pensamiento de Binford, que creemos que surge de las páginas comentadas, podemos decir que sólo los arqueólogos pueden trabajar con hechos relacionados directamente con episodios pasados; en cambio los etnógrafos pueden observar, como máximo, el funcionamiento de sistemas relativamente estables. Cuando se observa una situación etnográfica (del presente) lo que se ve es el funcionamiento de un sistema ya en el estado que ha motivado la búsqueda de una explicación.

No olvidemos que Binford hace etnoarqueología y no etnografía. ¿Pero ha logrado superar lo que él critica?

Lo que Binford desea es formular correctamente las preguntas que deben responder los arqueólogos. Frente a los modelos que pretenden tratar el problema "de los orígenes de la agricultura" señalará en el cap. 8 (págs. 210-229), las fallas metodológicas que existen en estos razonamientos e intentará, una vez más, describir algunas líneas de investigación que le parecen sugerentes, reconociendo que estas últimas son sólo ensayos.

Comienza estudiando las respuestas de Charles Darwin, "la agricultura es una forma de producción con ventajas evidentes y que el hombre la adoptaría inevitablemente si tiene conocimiento de ellas". Igualmente se refiere a los argumentos de Vere Gordon Childe, "teoría de la contigüedad o teoría del oasis". A partir de modificaciones del clima, producidas a fines del Pleistoceno y comienzo del Holoceno (creciente desecación), los grupos humanos (según Darwin y también Gordon Childe) se concentraron progresivamente en 
los valles de los ríos. Gordon Childe supuso que los hombres en estos medios ambientes tan favorables al practicar la agricultura pudieron proporcionar a los animales de pastoreo grandes cantidades de alimento a base de rastrojos. Robert Braidwood aportó primero una crítica al "esbozo de explicación" de Gordon Childe. Estudió el clima y concluyó que no se había producido cambios en el medio ambiente antes de la aparición de la Agricultura. Según Braidwood las comunidades de fines del Pleistoceno se familiarizaron con el medio ambiente; tomaron conciencia de él, lo conocieron, y lo manipularon en beneficio propio (creando la agricultura); en resumen los hombres se "instalaron en su medio ambiente".

Así todos estos estudiosos, y otros más recientes, postulan que la domesticación de plantas es el resultado de un proceso de aprendizaje prolongado; igualmente la agricultura es el resultado de un proceso emergente; la agricultura apareció porque ciertos grupos (no todos) tuvieron capacidad de aprender.

Binford, ya en 1968, se opuso a estas ideas, a este modelo de historia, insistiendo en la variable poblacional para explicar las innovaciones tecnológicas y formas de organización sociopolíticas más complejas. Pero su "esbozo de explicación" también fue rechazado por otros autores (argumentos ingenuos; no demostrados).

Al seguir revisando teorías sobre el origen de la agricultura, Binford resume brevemente las explicaciones: "según se desprende del argumento gradualista, el hombre desarrolla la agricultura porque posee una mayor información. De acuerdo con la visión del jardín del Edén aquel la practica rápidamente en medio ambientes ricos, hecho que favorece el sedentarismo; el sedentarismo, a su vez, se considera como un estímulo de la intensificación de la producción o de la experimentación de formas de producir el alimento suficiente en los espacios limitados situados alrededor de un asentamiento permanente (de ahí la agricultura). Una alternativa a este punto de vista (evidente, por otra parte) es que la adopción de la agricultura requiere un considerable grado de sedentarismo; por tanto, es de suponer que la gente se asienta con la práctica de la agricultura, porque ésta aparece con muchas posibilidades y permite que la decisión tomadas en contra del nomadismo se tome de acuerdo con el principio del mínimo esfuerzo".

Otra forma de gradualismo que imagina el principio de "un motor externo" (impulso continuo que viene del medio ambiente) proviene de Cohen, en 1977; quien plantea una crisis alimentaria a partir de un crecimiento continuo de las poblaciones; esto llevaría a éstas a implementar nuevos métodos para lograr el aumento de suministro de alimento.

Binford, se decide por volver a explorar los argumentos de Darwin, en lo que se refiere "a buscar las fuerzas matrices del cambio en la interacción entre el medio ambiente y el sistema adaptable considerado".

A partir de lo anterior insiste en que los cambios que conducen a la agricultura se deben más a consecuencias de las relaciones ecológicas alterna- 
das que a la acción continua, ya sea de algunos principios esenciales internos como de presiones externas inexorables; Binford le dará prioridad a la movilidad entre los cazadores y recolectores (a partir de sus observaciones etnoarqueológicas); pero si ésta era tan conveniente para estos grupos ¿qué los forzó a pasar de un sistema basado en la caza y recolección a un sistema de domesticar y cuidar las plantas? Cree que el apremio crítico deba haber sido algo que restó seguridad a la opción del nomadismo; y esto pudo haber sido el crecimiento de la población. Postula que los cazadores homo sapiens alcanzaron sus máximos de densidades poblacionales en las zonas templadas (y no en los bosques tropicales o en el desierto). El crecimiento que se produjo entre los cazadores y recolectores, en estos medio ambientes con temperatura media $14.4^{\circ} \mathrm{C}$, produjo problemas en sus relaciones sociales (de parentesco) y obviamente en su capacidad para alimentarse (escasean los animales, las plantas y frutos silvestres, etc.).

Estamos ante un modelo de "concentración poblacional", que es difícil de contrastar; sin embargo la información arqueológica permitiría sostener que grupos de cazadores en crisis intentarán resolverla domesticando animales y convirtiéndose en pastores; igualmente el inicio de un estilo de vida sedentario aparece interesante de considerar; sin embargo hay información contradictoria; en unas partes aparece primero que la agricultura y en otras se constituye como consecuencia de la agricultura. Si se considera que el nivel nutritivo de los alimentos también se debe tomar en cuenta, considerando que la proteína animal es importante, tanto a nivel nutritivo como de reproducción humana; si la presión demográfica es grande, y la caza escasea, como también la recolección de moluscos, entonces debería darse las circunstancias para cultivar algunas plantas (en América, maíz, en el cercano Oriente, trigo, etc.).

Estamos así ante un conjunto de explicaciones que dan "distintos significados al mismo modelo empírico demostrable en el registro arqueológico".

¿Cómo escoger entre todas estas interpretaciones? Su respuesta (que no es definitiva) es de nuevo metodológica; construir respuestas de rango medio "que hayan sido ideadas y probadas en contextos intelectuales apartados de las teorías sobre el comportamiento del pasado que intentamos evaluar".

Parece que Binford no puede responder como quisiera; su apoyo metodológico centrado en el análisis etnográfico (con perspectiva arqueológica) no es suficiente para responder las grandes preguntas que él mismo se ha formulado. Creo que, sin embargo, lo han ayudado (y a nosotros también) a apartar "argumentos acomodaticios post-hoc" que apoyan teorías tautológicas. Pero queda claro después de leer su valioso libro que no ha podido crear los instrumentos necesarios para medir las variables que se observan en el registro arqueológico. Tal vez el reto sea imposible de responder, por lo menos según nuestros actuales métodos y teorías.

Se le ha criticado (I. Hodder: Interpretación en Arqueología. Corrientes actuales. 1994) especialmente el uso que hace del concepto de Teoría de 
Alcance Medio, puesto que el término "resulta redundante", ya que "toda teoría tiene formas generales y aplicadas".

Recordemos que el concepto de Teoría de alcance medio fue expuesta por el sociólogo R.K. Merton, en la década de 1950, en su libro Teoría Social y Estructura Social; y que tenía como finalidad explicar un área limitada de la conducta humana; además era intermedia respecto de las hipótesis de trabajo menores y las especulaciones omnímodas que pretenden explicar la conducta social humana.

La simpatía de Binford por esta medotología de rango medio creo que se puede explicar por su esfuerzo de apartarse de los "arqueólogos sociales", poniendo al servicio de su pensamiento los datos de la realidad pasada.

Sin embargo, como ya lo hemos comentado, nos parece que Binford - a pesar de sus esfuerzos - en el análisis de los contextos arqueológicos que estudia, opta por concluir respuestas teóricas que no sirven a sus contextos particulares sino que los extiende a otros contextos arqueológicos. Es decir no puede dejar de generalizar, aunque con mejores argumentos científicos que los "filósofos sociales".

Es probable que su problema epistemológico es que busca modelos de comportamiento universales, y aunque reconoce diferencias, tiende a darles sentido a través de los métodos etnoarqueológicos, traspasando así las barreras del tiempo (Presente etnológico-Pasado prehistórico).

Tal vez si los arqueólogos se centrasen en una temática particular, por ejemplo arqueología espacial, se estudiasen los contextos habitacionales, la distribución de los diversos restos culturales, y de otros tipos, y se intentara responder teóricamente lo que se observa en esos yacimientos sin pretender generalizar, ni menos apoyarse para esto en realidades culturales separadas por miles de años, se podría hacer uso de explicaciones no globales, es decir de rango medio. No se trata de oponerse a explicaciones ni a la búsqueda de encontrar el sentido de los hechos del pasado; todo lo contrario, lo que recomendamos es hacerlo a través de yacimientos y contextos culturales que se puedan controlar bien; entonces las conclusiones, las explicaciones, corresponderían a esas realidades y no a otras. Binford tiene razón cuando protesta por las generalizaciones, poco serias, de los arqueólogos filósofos. 